\title{
CORRIGENDUM
}

\section{The permeability transition pore complex in cancer cell death}

\author{
C Brenner and S Grimm
}

Oncogene (2006) 25, 6678. doi:10.1038/sj.onc.1210020

\section{Correction to:}

Oncogene (2006) 25: 4744 4756. doi:10.1038/sj.onc.1209609

Published online 30 January 2006

Figure 1 of this paper contains a large portion of Figure 4 from an article by Paul S Brookes et al., published in the American Journal of Physiology-Cell-Physiology.

The following should be added to the figure legend: 'Adapted with permission from Brookes PS, Yoon Y, Robotham JL, Anders MW, Sheu S-SS. (2004). Calcium, ATP and ROS: a mitochondrial love-hate triangle. Am J Physiol Cell Physiol 287: C817-C833.'

Copyright (2005) National Academy of Sciences, USA.

The authors would like to apologize for not citing this originally.

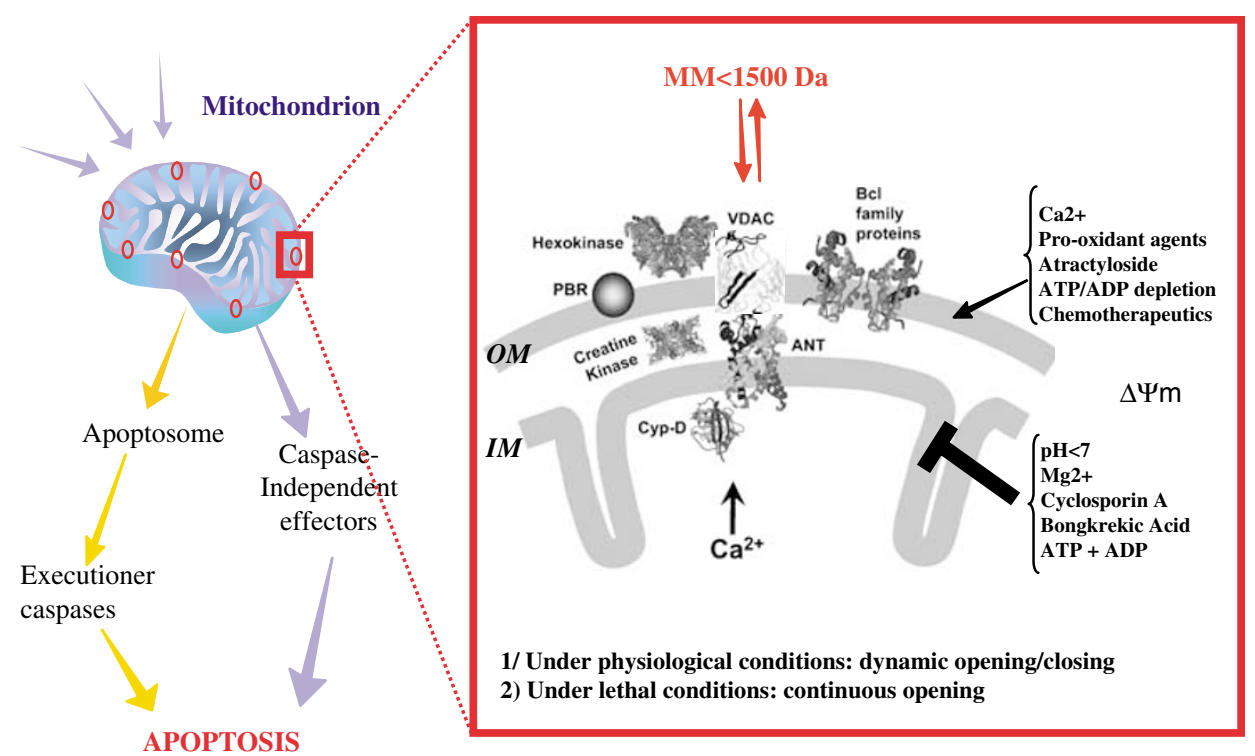

Figure 1 The permeability transition pore (PTP) function. During apoptosis, many signals can converge on the mitochondrion to regulate the mitochondrial membrane permeability. In response to calcium $\left(\mathrm{Ca}^{2+}\right)$, atractyloside, adenine nucleotide depletion, chemotherapeutics and pro-oxidant agents, the membrane permeabilization can result from the opening of PTP as a large unspecific channel and leads to the release of proapoptotic factors into the cytosol. In contrast, many agents (CsA, bongkrekic acid, $\mathrm{Mg}^{2+}$, high ADP/ATP) or conditions $(\mathrm{pH}<7)$ promote the closure of the PTP and prevent apoptosis. When available, PDB structure models for PTP members have been inserted. 